\title{
The surfaces of the Ceratonia siliqua L. (Carob) leaflet: insights from physics and chemistry
}

S. Rodríguez, ${ }^{1}$ J. Rocha, ${ }^{1,2}{ }^{*}$ M. Fernandes, ${ }^{1,3,}$ A. P. Ravishankar, ${ }^{4}$ N. Steinbrück, ${ }^{5}$ R. Cruz, ${ }^{6}$ E. Bacelar, ${ }^{7}$ G. Kickelbick, ${ }^{5}$ S. Anand,${ }^{4}$ A. L. Crespi, ${ }^{2,7}$ S. Casal, ${ }^{6}$ V. de Zea Bermudez ${ }^{1,3, *}$

\section{Botanical information about Ceratonia siliqua $L$.}

C. siliqua belongs to the Fabaceae family and Caesalpinioidea subfamily.

Genus Ceratonia shows Rand flora occurrences, ${ }^{1}$ according to the vicariant distribution of both species included in this genus: the Mediterranean-Arabian-Saharian C. siliqua, and the south Arabian-Omanian C. oreothauma Hillc. \& al..

The current ecological preference of the $C$. siliqua taxon is the sclerophyllous habitats (in particular the Maquis) which comprise a scrubland vegetation adapted to prevent moisture loss, primarily composed of leathery, broad-leaved evergreen shrubs or small trees ${ }^{2}$ with pre-forest thermo-Mediterranean woody species. ${ }^{3}$

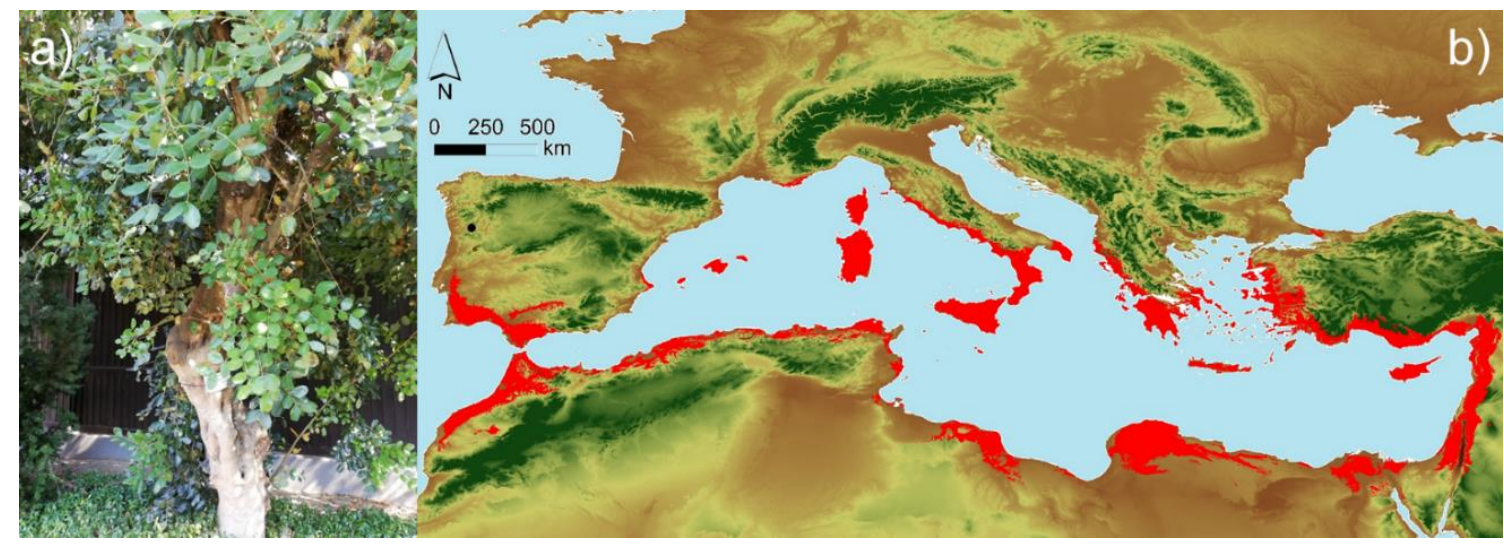

Figure S1. C. siliqua: photograph of a tree located in the Botanical Garden of UTAD (a), and potential natural habitat distribution (red areas) (b).

(1) Mairal, M.; Sanmartín, I.; Pellissier, L., Lineage -specific climatic niche drives the tempo of vicariance in the Rand Flora. J. Biogeogr., 2017, 44(4), 911-923.

(2) Rigo, D.; Caudullo, G. Quercus ilex in Europe: Distribution, habitat, usage and threats. European Atlas of Forest Tree Species (pp.130-1312), European Union: Luxembourg, 2016.

(3) Lefèvre, F.; Fady, B. Introduction to Mediterranean Forest Systems: Mediterranean Basin. In Insects and Diseases of Mediterranean Forest Systems (pp. 7-28), Springer, Cham, 2016. 
Table S1. Results of the total waxes extraction in the $C$. siliqua leaflets.

\begin{tabular}{cccccc}
\hline $\begin{array}{c}\text { mass } \\
(\mathbf{g})\end{array}$ & $\begin{array}{c}\text { dry mass } \\
(\mathbf{g})\end{array}$ & $\begin{array}{c}\text { leaflet } \\
\mathbf{a r e a} \\
\left(\mathbf{c m}^{2}\right)\end{array}$ & $\begin{array}{c}\text { wax mass } \\
(\mathbf{m g})\end{array}$ & $\begin{array}{c}\text { total waxes } \\
\left(\mu \mathbf{g} / \mathbf{c m}^{2}\right)\end{array}$ & $\begin{array}{c}\text { total waxes } \\
(\mathbf{m g} / \mathbf{g})\end{array}$ \\
\hline 2.6180 & 1.1256 & 87.97 & 7.0 & 79.57 & 6.2189 \\
\hline 1.4257 & 0.5715 & 50.98 & 3.9 & 76.50 & 6.8241 \\
\hline 2.9574 & 1.1801 & 94.14 & 7.7 & 81.79 & 6.5248 \\
\hline 1.7992 & 0.7467 & 59.67 & 4.7 & 78.76 & 6.2943 \\
\hline 2.1635 & 0.8340 & 70.83 & 5.3 & 74.82 & 6.3549 \\
\hline 2.6970 & 0.9913 & 88.33 & 6.6 & 74.71 & 6.6579 \\
\hline
\end{tabular}



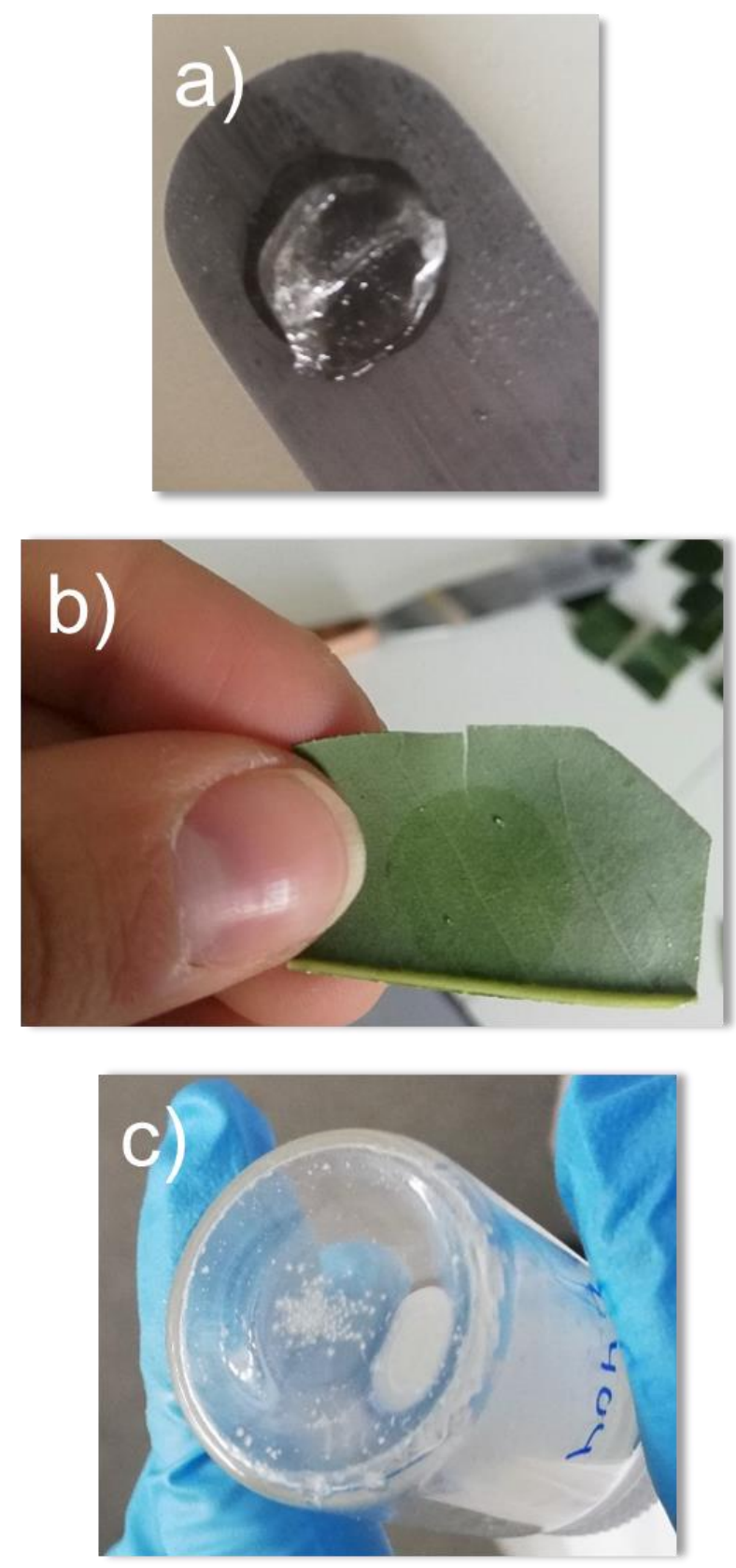

Figure S2. Mechanical (cryo-adhesion) extraction of the cuticular waxes of the surface of $C$. siliqua leaflets: (a) drop of glycerol; (b) appearance of the abaxial surface after epicuticular wax removal; (c) epicuticular wax recovered after chloroform evaporation. 
Table S2. Chromatographic information regarding the most abundant aliphatic compounds in the cuticular waxes of $C$. siliqua leaflet.

\begin{tabular}{|c|c|c|c|}
\hline Compounds & $\begin{array}{l}\text { Theoretical retention } \\
\text { index }\end{array}$ & Match & $\begin{array}{c}\text { Reversed } \\
\text { Match }\end{array}$ \\
\hline nonanoic acid (TMS derivative)* & 1355 & 820 & 860 \\
\hline decanoic acid (TMS derivative)* & 1450 & 849 & 974 \\
\hline hexadecane* & 1600 & 916 & 941 \\
\hline 2,6,11,15-tetramethyl-hexadecane & 1792 & 860 & 866 \\
\hline myristic acid (TMS derivative) & 1850 & 839 & 849 \\
\hline 1-hexadecanol (TMS derivative)* & 1958 & 824 & 905 \\
\hline palmitic acid (TMS derivative)* & 2050 & 935 & 940 \\
\hline stearic acid (TMS derivative)* & 2246 & 889 & 892 \\
\hline 1-monomyristin (2TMS derivative) & 2418 & 877 & 889 \\
\hline 2-monopalmitin (2TMS derivative) & 2558 & 822 & 883 \\
\hline 1-monopalmitin (2TMS derivative)* & 2607 & 950 & 965 \\
\hline 2-monostearin (2TMS derivative) & 2772 & 840 & 885 \\
\hline 1-monostearin (2TMS derivative)* & 2806 & 942 & 942 \\
\hline lignoceric acid (TMS derivative) & 2838 & 861 & 902 \\
\hline 1-hexacosanol (TMS derivative) & 2940 & 948 & 948 \\
\hline $\begin{array}{l}\text { 2,3-dihydroxypropyl icosanoate (2TMS } \\
\text { derivative) }\end{array}$ & 2998 & 662 & 735 \\
\hline 1-heptacosanol (TMS derivative) & 3027 & 929 & 929 \\
\hline 1-octacosanol (TMS derivative)* & 3138 & 911 & 911 \\
\hline 1-triacontanol (TMS derivative) & 3334 & 938 & 939 \\
\hline
\end{tabular}

*Compounds whose retention times and $\mathrm{m} / \mathrm{z}$ spectra were compared to those of reference standards.

TMS, trimethylsilyl. 
A

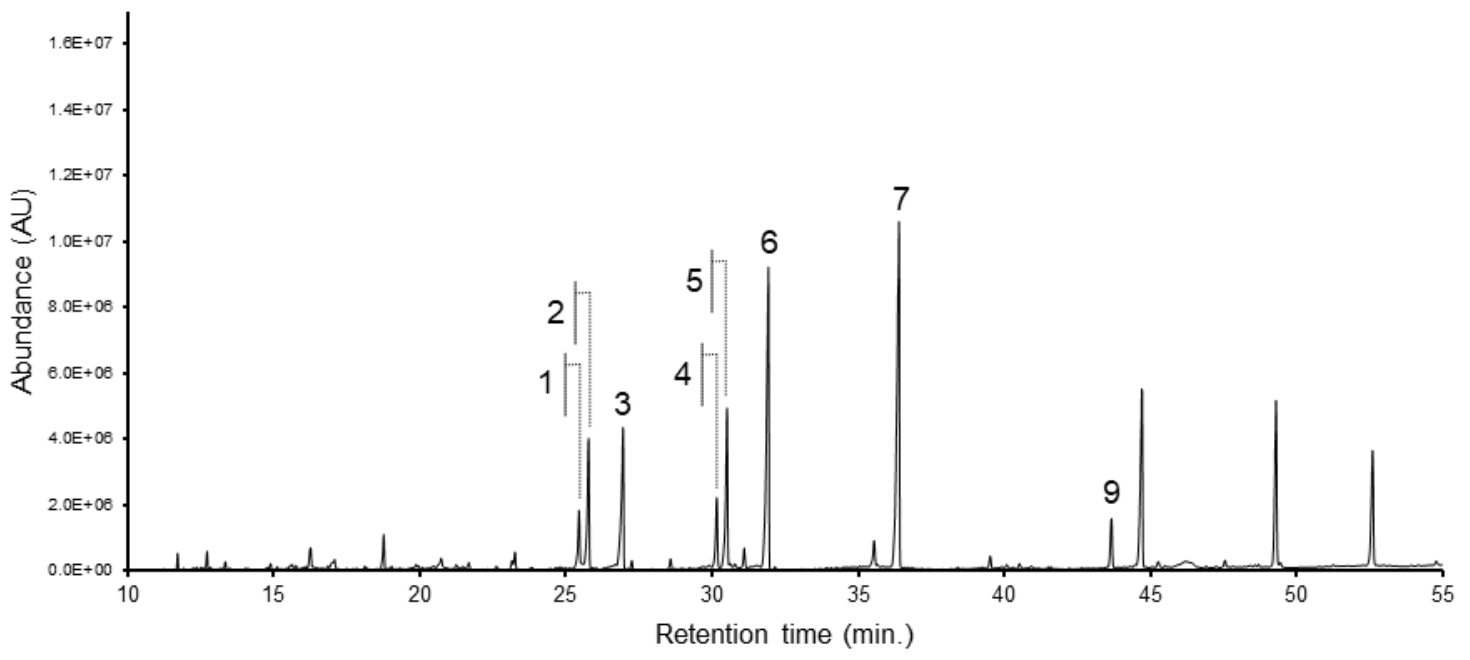

B

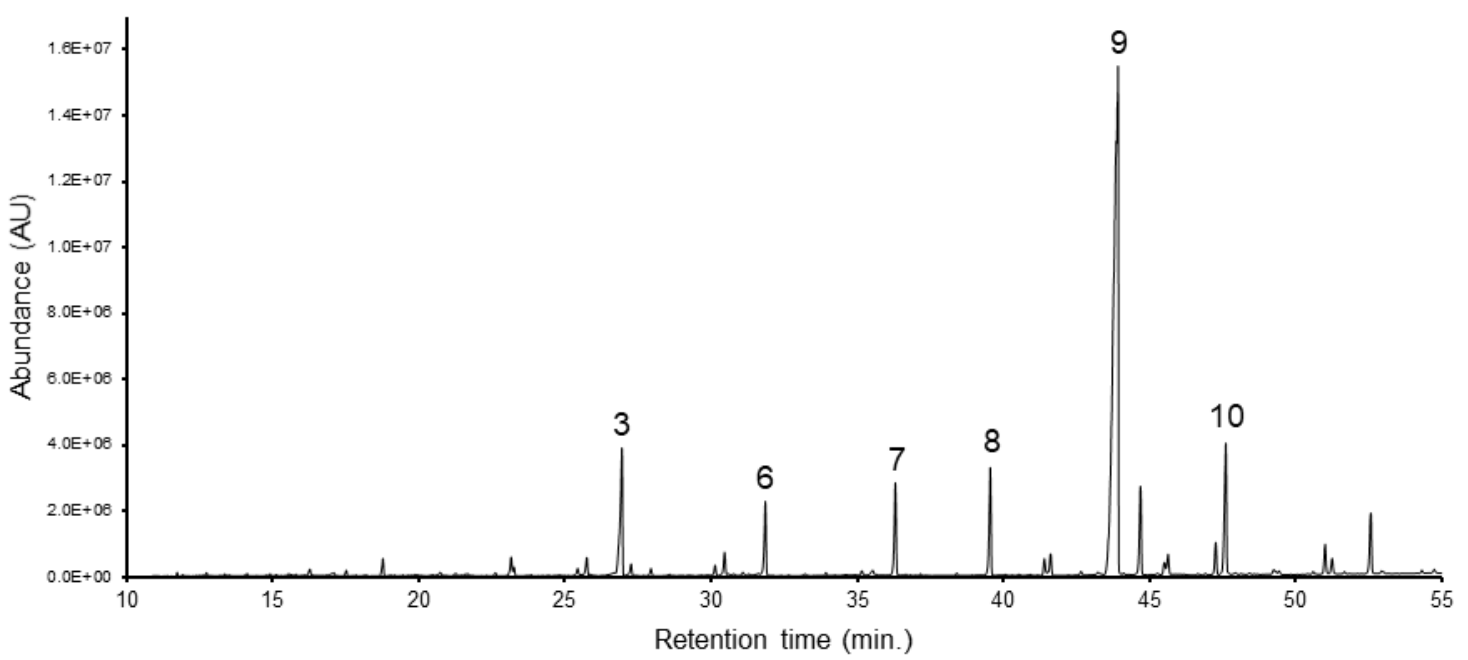

Figure S3. GC-FID Chromatograms of the epicuticular waxes of the adaxial (A) and abaxial (B) surfaces of C. siliqua leaflet: (1) palmitic acid*; (2) 1-heptadecanol*; (3) tetracosane (internal standard); (4+5) stearic acid*; (6) 1-monopalmitin*; (7) 1monostearin*; (8) 1-hexacosanol*; (9) 1-octacosanol*; (10) 1-triacontanol*. Note: * trimethylsilyl derivative. 

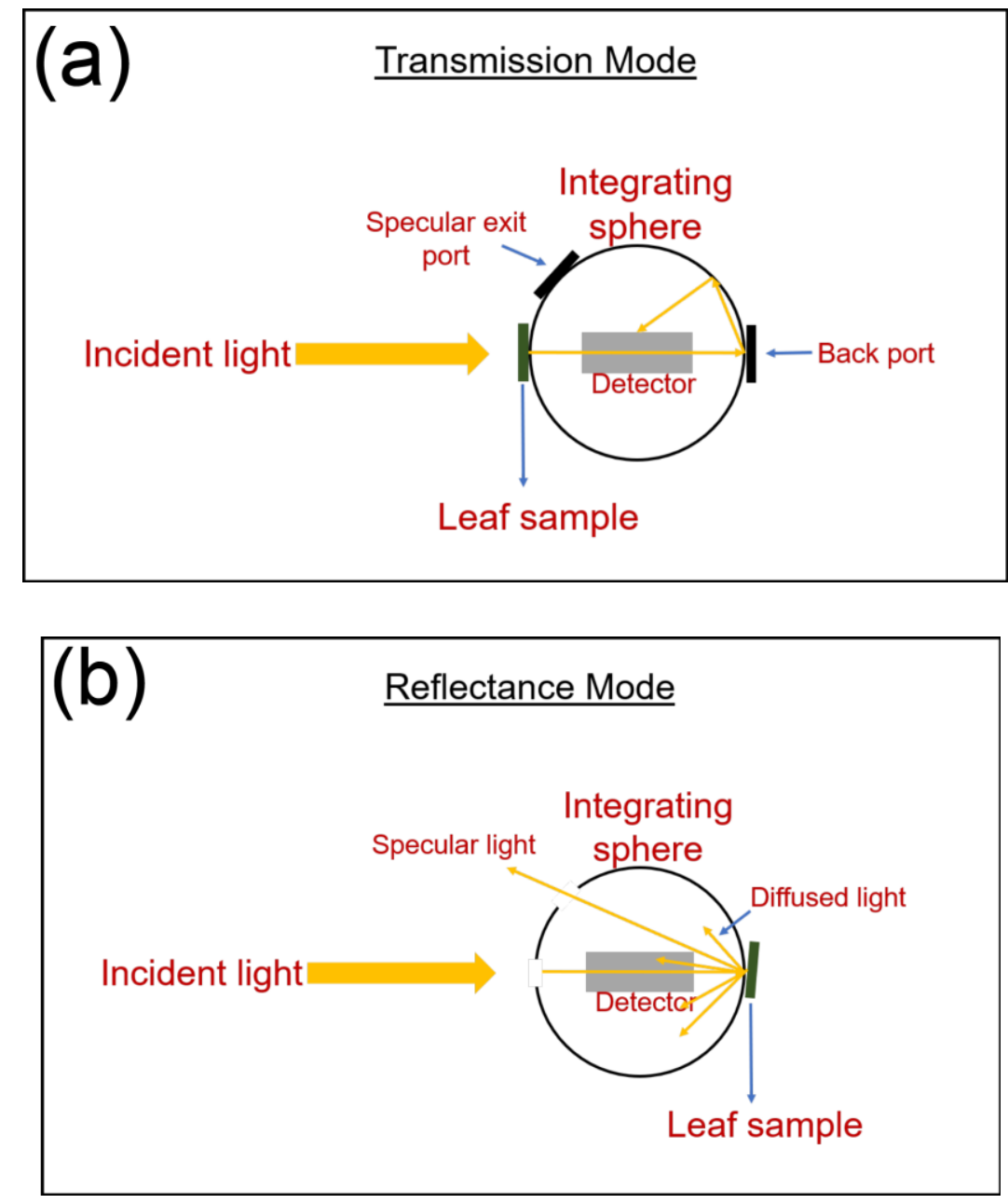

Figure S4. Optical spectrophotometer set-up. (a) Transmittance mode setup - to measure transmittance through a sample placed at the front port of the integrating sphere and (b) reflectance mode setup - to measure reflectance from a sample placed at the back port. 

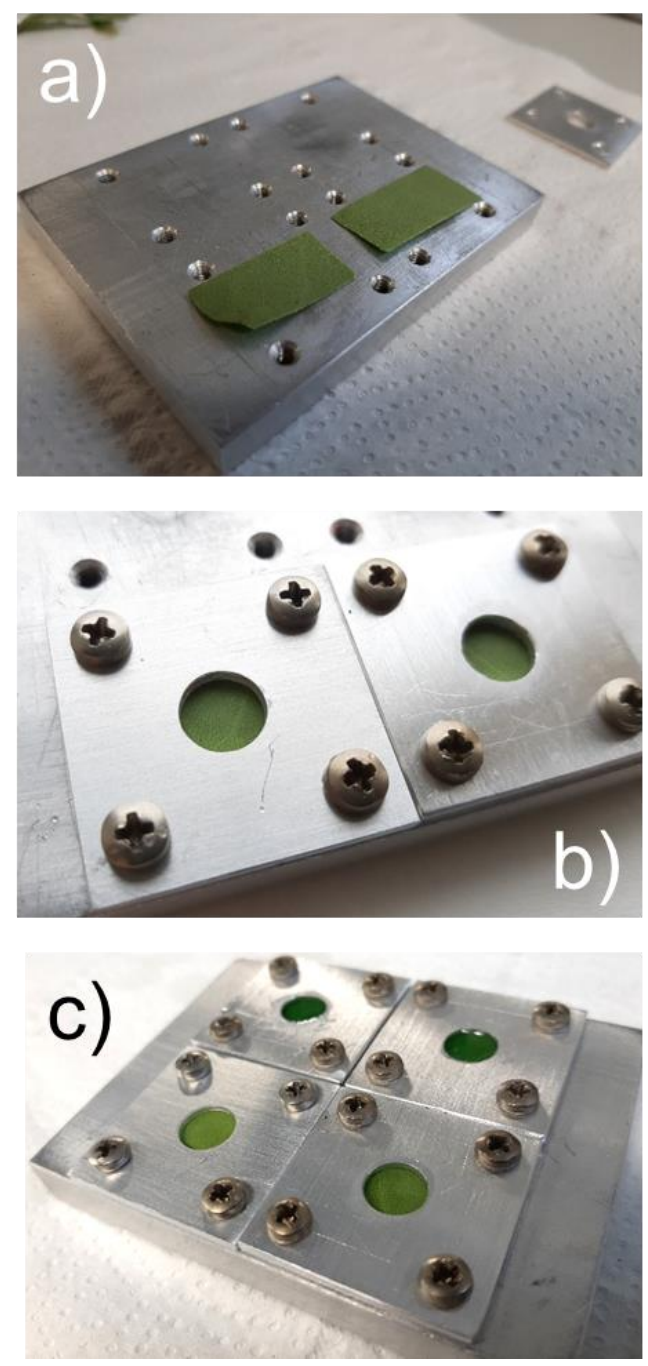

Figure S5. Set-up used for the production of the negative PDMS replica of the abaxial surface of $C$. siliqua leaflets: (a) positioning of the leaflet on an Al baseplate, (b) fixation of the leaflets with a screwed Al frame, and (c) filling of the holes with the PDMS mixture to be subsequently cured. 

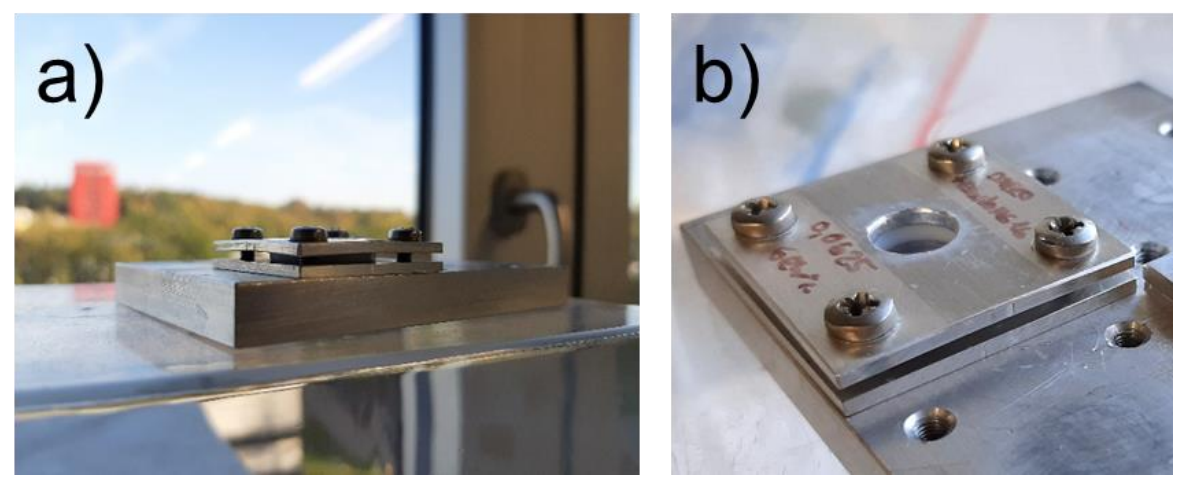

Figure S6. Set-up used for the production of the positive PMPS replica of the abaxial surface of a C. siliqua leaflet: side (a) and top (b) views of the fixed Al stack incorporating the negative PDMS replica. 


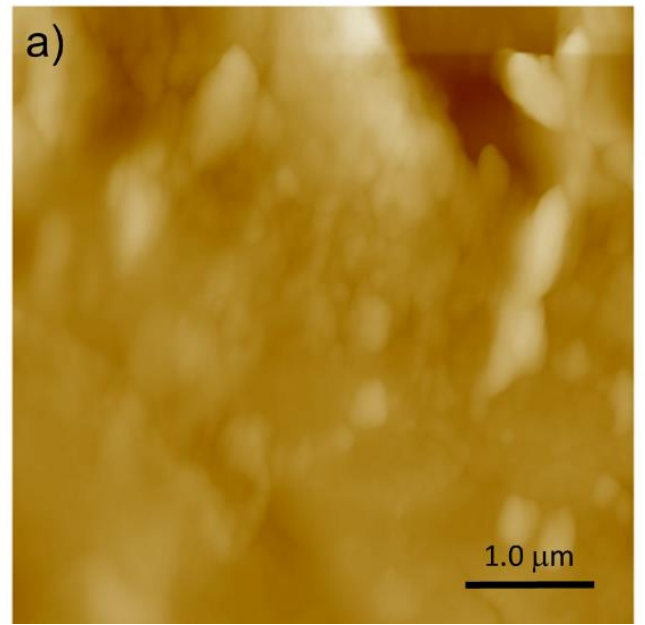

b)

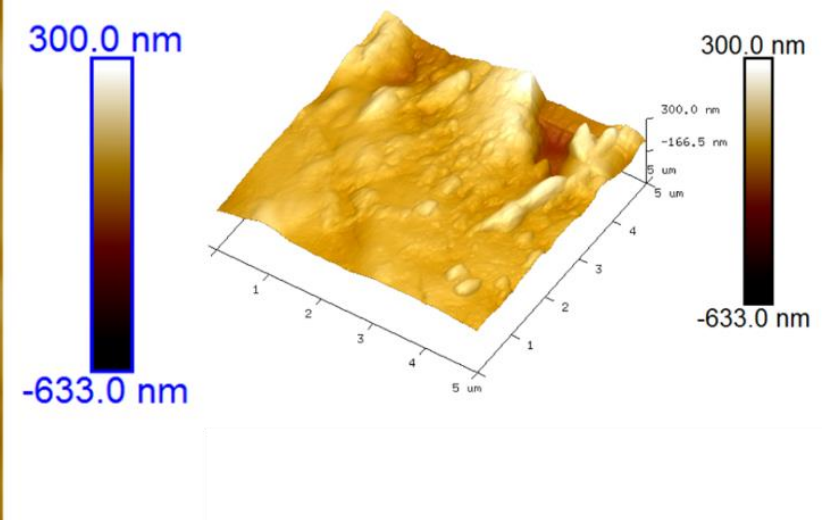

Figure S7. AFM topographical 2D (a) and 3D (b) images of a representative region of the adaxial surface of a $C$. siliqua leaflet. Some isolated cross-like topography feature, similar to what is observed in SEM images, is visible in the right corner of (b). 


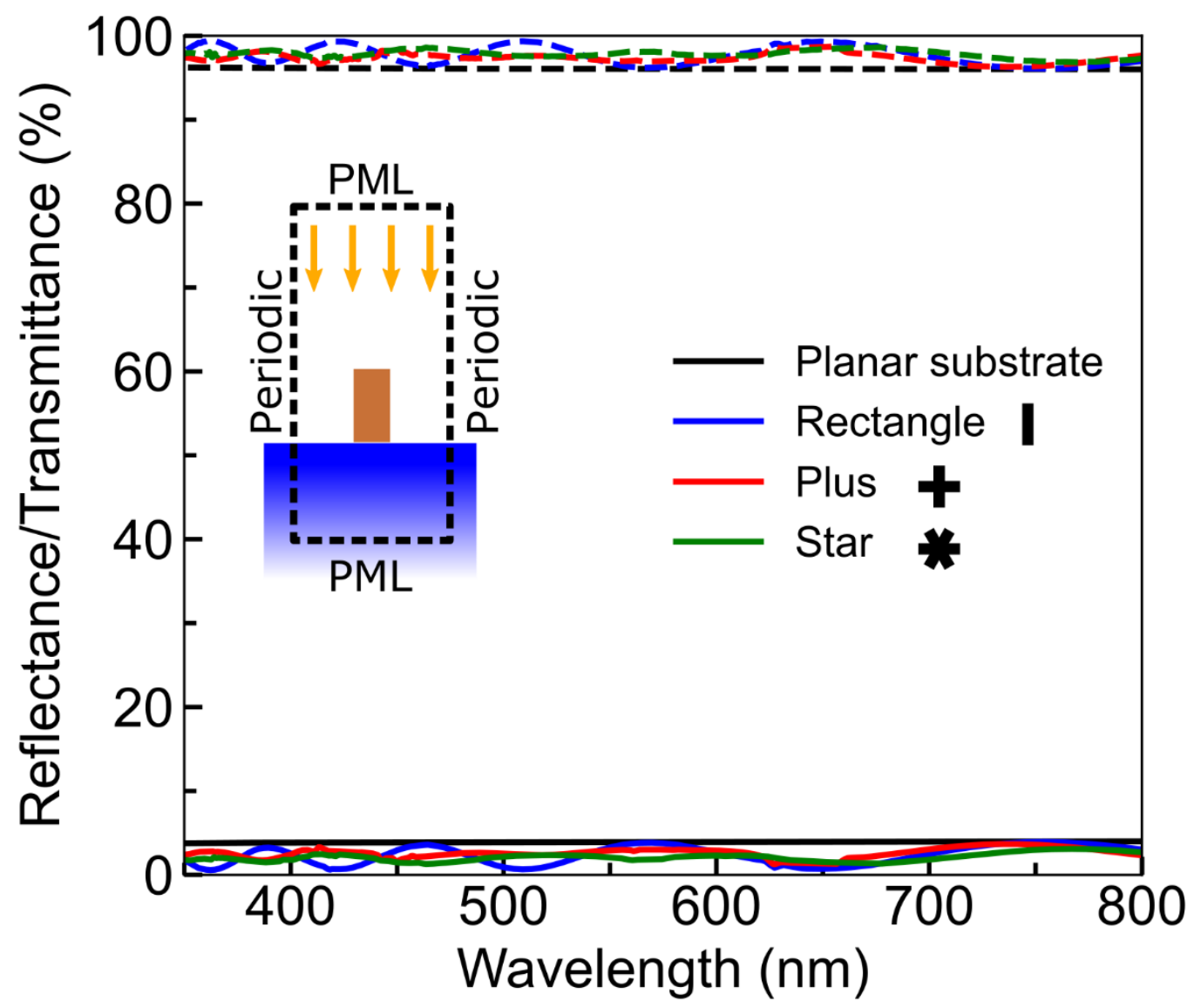

Figure S8. Transmittance (dashed lines) and reflectance (solid lines) results are presented from the finite difference time domain (FDTD) simulations on different wax structures placed on a planar substrate. The 3D wax structures (rectangle, plus, and star) are simplified geometrical approximations of the wax features of the adaxial side of $C$. siliqua, as seen in Figure 4. The rectangular wax block has a height and a length of 1000 $\mathrm{nm}$ and a width of $100 \mathrm{~nm}$. The average estimate of the dimensions of the block were obtained from Figure 4c. Each arm of the plus and the star structures have the same dimensions as those of the rectangular block. The inset describes the simulation set-up consisting of a plane wave source $(350-800 \mathrm{~nm}$ ) incident normally (z-axis) on the rectangular wax block placed on a planar substrate. Perfectly matched layers (PMLs) were used in the light incident direction and periodic boundary conditions were employed in 
the other two directions ( $\mathrm{x}$ - and $\mathrm{y}$-axis) with a period of $250 \mathrm{~nm}$ (average gap between the wax structures). Based on previous estimations of the refractive index (RI) of epicuticular wax layer, ${ }^{4,5}$ an average RI value of 1.5 was assumed for the wax structure and the substrate. The surface wax structures and the substrate were both considered as nonabsorbing in the investigated spectral region. The simulation results show that, in comparison with the experimental results (Figure 8), the contribution of the wax layer to the reflectance is minimal (less than 4\%) at normal light incidence. This implies that the scattering from the interior layers of a leaf play an important role in the enhancement of reflectance. Thus, instead of a planar substrate, a more intricate modelling of the leaf is necessary that, not only considers the RI of cell walls, but also parameters associated with leaf interior, such as absorption coefficient of the chlorophyll content, multilayer refractive índices, and scattering coefficient due to a specific arrangement of cellular layers.

(4) Allen, W.A., Gausman, H.W., Richardson, A.J., Thomas, J.R. Interaction of isotropic light with a compact plant leaf. JOSA, 1969, 59(10), 1376-1379.

(5) Bousquet, L., Lachérade, S., Jacquemoud, S., Moya, I. Leaf BRDF measurements and model for specular and diffuse components differentiation. Remote Sens. Environ., 2005, 98(2-3), 201-211. 

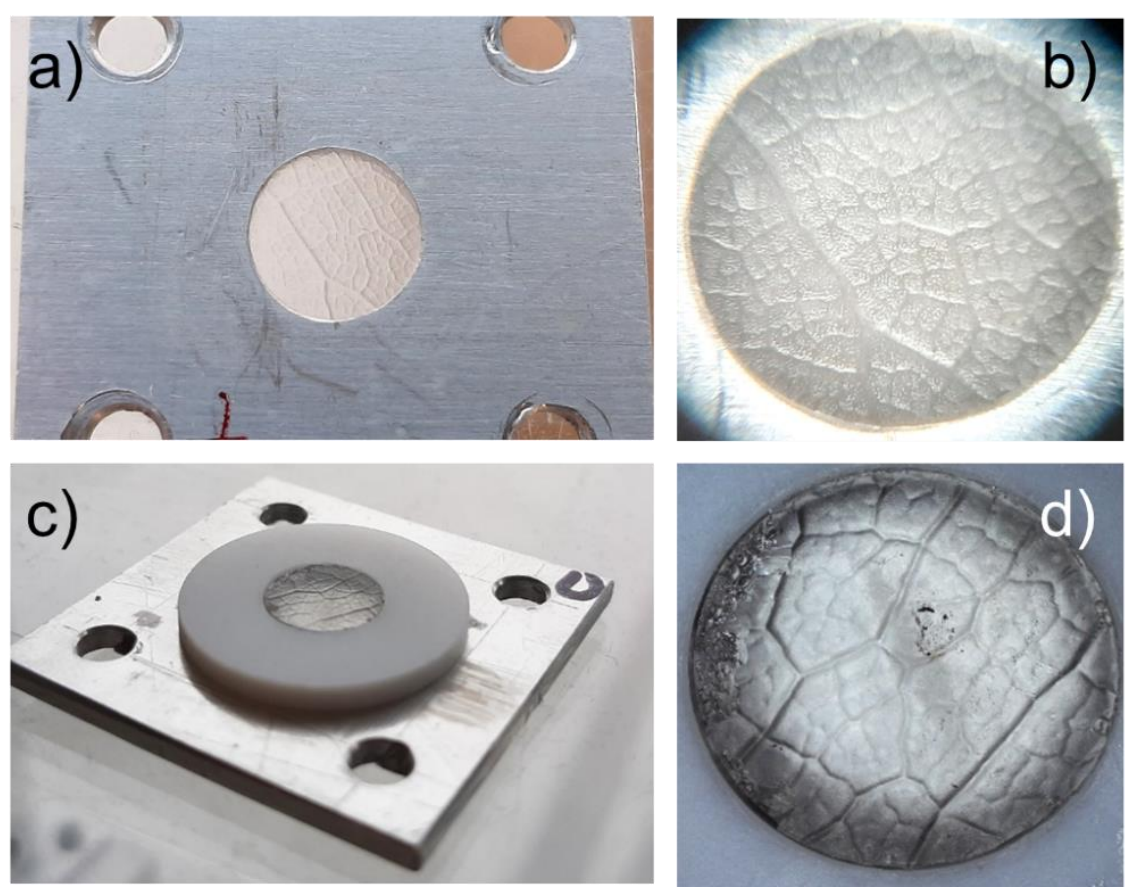

Figure S9. Negative PDMS $(a, b)$ and positive PMPS $(c, d)$ replicas of the abaxial surface of a $C$. siliqua leaflet. 

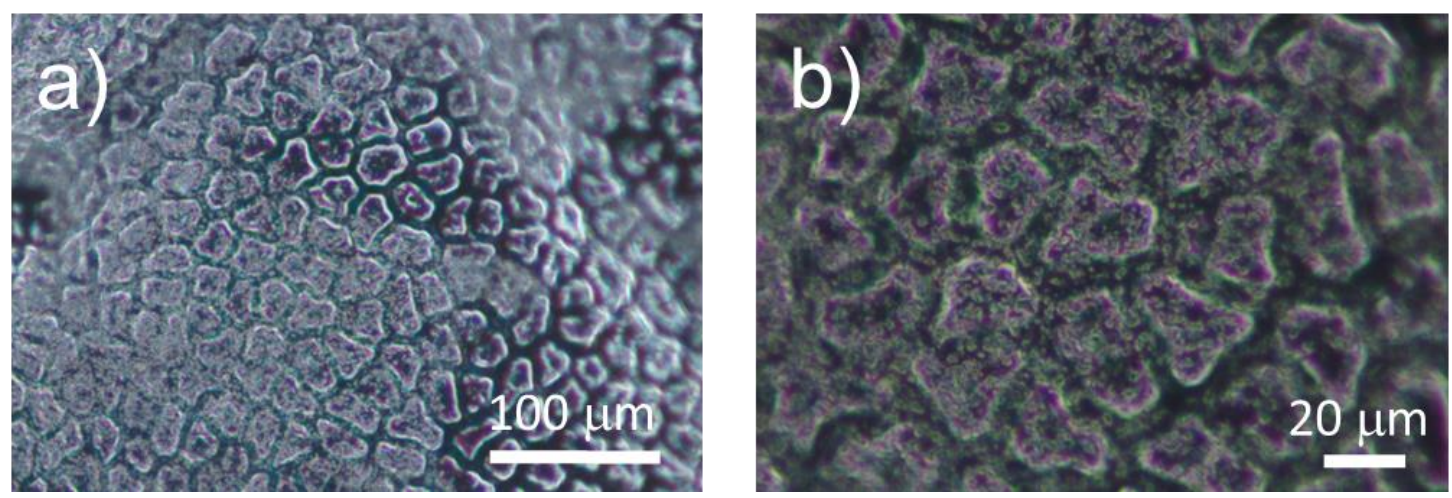

Figure S10. POM images (parallel polarizers) of the positive PMPS replicas of the abaxial surface of a $C$. siliqua leaflet. 


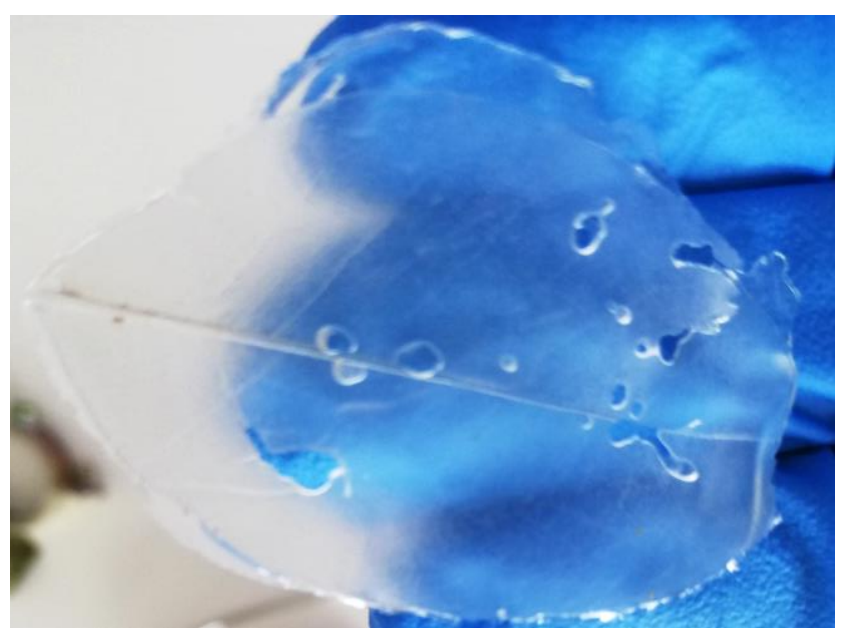

Figure S11. Physical appearance of the d-U(2000)-based negative replica of the abaxial surface of a $C$. siliqua leaflet after removal from the Teflon mold with the help of a spatula. Because the film produced was very thin, this procedure led to the creation of a few holes in the film. 

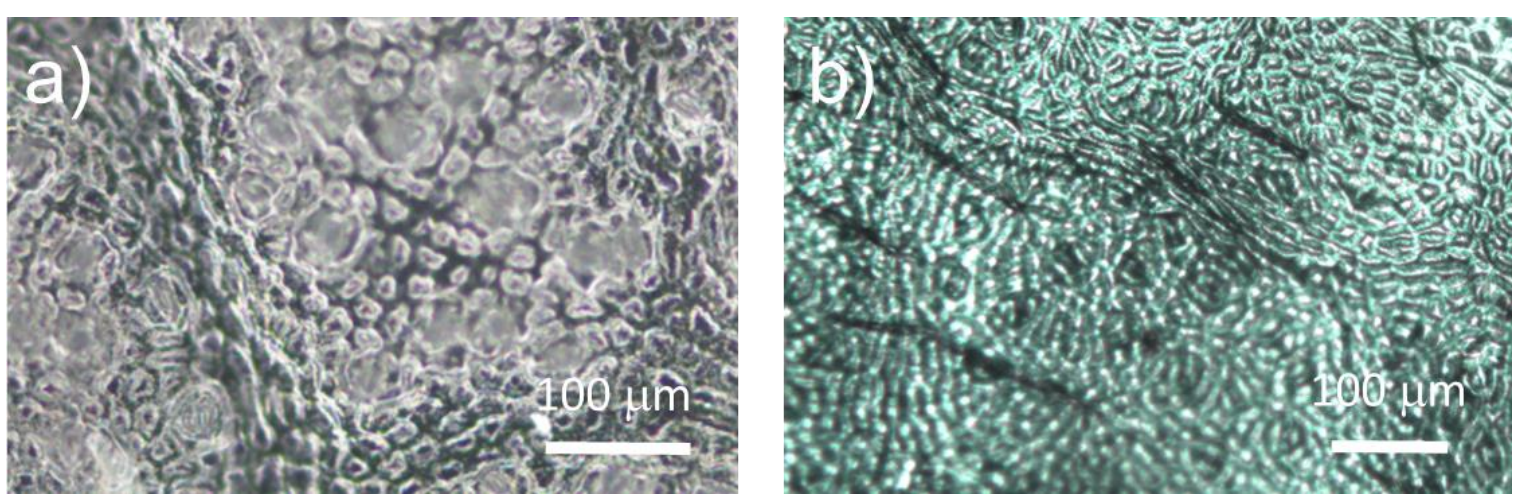

Figure S12. POM images of the negative replicas of the abaxial surface of a $C$. siliqua leaflet: PDMS (parallel polarizers) (a) and d-U(2000) (crossed polarizers) (b). 